\title{
Comparison of Morphine and Tramadol in Transforaminal Epidural Injections for Lumbar Radicular Pain
}

Department of Anesthesiology and Pain Medicine, Daegu Wooridul Spine Hospital, Daegu, Korea

Chan Hong Park, MD

\section{Background:}

Transforaminal epidural steroid injections are known to reduce inflammation by inhibiting synthesis of various proinflammatory mediators and have been used increasingly. The anti-inflammatory properties of opioids are not as fully understood but apparently involve antagonism sensory neuron excitability and pro-inflammatory neuropeptide release. To date, no studies have addressed the efficacy of transforaminal epidural morphine in patients with radicular pain, and none have directly compared morphine with a tramadol for this indication. The aim of this study was to compare morphine and tramadol analgesia when administered via epidural injection to patients with lumbar radicular pain.

\section{Methods:}

A total of 59 patients were randomly allocated to 1 of 2 treatment groups and followed for 3 months after procedure. Each patient was subjected to C-arm guided transforaminal epidural injection (TFEI) of an affected nerve root. As assigned, patients received either morphine sulfate $(2.5 \mathrm{mg} / 2.5 \mathrm{ml})$ or tramadol $(25 \mathrm{mg} / 0.5 \mathrm{ml})$ in combination with $0.2 \%$ ropivacaine $(1 \mathrm{ml})$. Using numeric rating scale was subsequently rates at 2 weeks and 3 months following injection for comparison with baseline.

\section{Results:}

Both groups had significantly lower mean pain scores at 2 weeks and at 3 months after treatment, but outcomes did not differ significantly between groups.

\section{Conclusions:}

TFEI of an opioid plus local anesthetic proved effective in treating radicular pain. Although morphine surpassed tramadol in pain relief scores, the difference was not statistically significant. (Korean J Pain 2013; 26: 265-269)

\section{Key Words:}

chronic pain, epidural analgesia, injection, morphine, radicular pain, spinal.

Received March 28, 2013. Revised May 23, 2013. Accepted May 23, 2013.

Correspondence to: Chan Hong Park, MD

Department of Anesthesiology and Pain Medicine, Daegu Wooridul Spine Hospital, 648 Gugchaebosang-ro, Jung-gu, Daegu 700-732, Korea Tel: +82-53-212-3179, Fax: +82-53-212-3049, E-mail: magary1@hanmail.net

(ㄷ) This is an open-access article distributed under the terms of the Creative Commons Attribution Non-Commercial License (http:// creativecommons.org/licenses/by-nc/3.0/), which permits unrestricted non-commercial use, distribution, and reproduction in any medium, provided the original work is properly cited.

Copyright (c) The Korean Pain Society, 2013 


\section{INTRODUCTION}

Chronic radicular pain is often accompanies by lumbar disc herniation, spinal stenosis, or degenerative spondylolisthesis. Lumbar disc herniation is the most common cause of such pain, which typically radiates from the back into the leg along dermatomal distribution of an irritated nerve root. Moreover, there is evidence that herniated nucleus pulposus also generates intense inflammation, so epidural injection of corticosteroids constitutes a reasonable treatment option [1,2]. Indeed, research suggests that this approach is corroborated by the biochemical construct of radicular pain [3].

Epidural steroid injections do relieve radicular pain and may be given via interlaminar, transforaminal, or caudal route. Transforaminal epidural steroid injections for the treatment of lumbar radicular pain have become more commonly used in the last years [4], with ant-inflammatory effects of steroids credited for therapeutic success [5]. In previous studies, $55 \%-84 \%$ of patients reported shortto moderate-term pain relief $[4,6]$. In contrast, periradicular infiltration of steroids is comparatively ineffective [7], possibly owing to the lack of significant systemic inflammatory component in milieu of chronic low back pain [8].

The presence of opioid receptors at the spinal level has been well known for many year, and the excellent analgesia provided by morphine post-operatively and/or post-cesarean section is well-known [9-11]. Tissue injury and inflammation leads increased expression of dorsal root neuronal opioid receptors [12]. Opioid analgesia is thus consequence of inhibited sensory neuroral excitability, in addition of pro-inflammatory neuropeptide release [13].

There is little literature, however, on the use of opioid to treat radiculopathy. According to one article [14], CTguided selective nerve root infiltrations with the supplement of tramadol is found to be highly effective for treatment of persistent radiculopathies. Tramadol has a lower affinity to opioid receptors than others, mainly on $\mu^{-}$ receptors, but it also inhibits the reuptake of serotonin and noradrenalin. In its intravenous form, it is a well-established analgesic and has proved safe and effective in epidural applications for pain, especially in postoperative pain relief $[9,14,15]$. However, in comparing cervical epidural steroid injection with and without morphine in chronic cervical radicular pain, no differed in pain reduction [16].
There is no published report on the efficacy of transforaminal epidural morphine in patients with radicular pain, and no direct comparisons of morphine and tramadol have yet been reported this indication. The aim of the present study was to comparing morphine and tramadol analgesia when given via epidural injection to patients with lumbar radicular pain.

\section{MATERIALS AND METHODS}

This randomized, single-center study study was conducted with the full approval of the local Institutional Review Board and written informed consent was obtained from all subjects. A total of 59 patients between 18 and 80 years, of age were enrolled for treatment and then followed for 3 months. All had a diagnosis of lumbar radicular pain based on pain distribution and magnetic resonance imaging (MRI) showing intervertebral disc herniation, spinal stenosis, or other spinal disease. Exclusion criteria were as follow: oral, peripheral, or epidural steroid use within prior 3 months, oral temperature greater than 100.4, pregnancy, cognitive impairment, inability to give consent, use of aspirin, clopidogrel, warfarin, or heparin in the prior 2 weeks, history of bleeding disorders, history of lumbar surgery and, axial pain.

The same anesthesiologist performed each $\mathrm{C}$-armguided transforaminal epidural injection (TFEI) (of affected nerve root) on outpatient setting. In patients with S1 radiculopathy, the needle was placed into the foramen at S1 at the level of the L5/S1 disc. Correct needle placement was verified by application of $0.5 \mathrm{ml}$ of a contrast agent. Patients were randomly allocated to 1 of 2 groups, receiving TFEI of $0.2 \%$ ropivacaine $(1 \mathrm{ml})$ in combination with morphine sulfate $2.5 \mathrm{mg}(2.5 \mathrm{ml})$ or tramadol $25 \mathrm{mg}(0.5 \mathrm{ml})$ plus normal saline [17]. Required volumes were extrapolated from contrast needed to desired coverage. Patients then were observed for 2 hours, noting any adverse effects during or after the injection.

The primary outcome parameter was lower extremities radicular pain as measured by a numeric rating scale (NRS). Patients were evaluated at baseline, then post-injection at 2 weeks, and at 3 months. During the first 2 weeks, all subjects received NSAIDs, and muscle relaxants. Patients unresponsive to these medications were given opioid or non-opioid analgesics after the first follow-up visit. 
The efficacy of injection was estimated as the changes in the pain scores from before to after the epidural injection. The Mann-Whitney U test was used for statistical analysis, with type I error rate of $<0.05$ was considered significant. Sample size (N = 59) was specified in advance to provide $80 \%$ power of detecting a difference in the amount of pain score change. All statistical analysis was performed on 56 subjects (excluded 3 operation patients), and SPSS software, version 14.

\section{RESULTS}

The 59 patients were randomized into 2 groups, there was no significant difference between the groups with respect to age, gender, and targeted spinal segment (Table 1).

Table 1. Patients Demographic and Clinical Features

\begin{tabular}{|c|c|c|}
\hline$N=59$ & $\begin{array}{l}\text { Morphine } \\
(n=32)\end{array}$ & $\begin{array}{l}\text { Tramadol } \\
(n=27)\end{array}$ \\
\hline Age (yrs) & $53.9 \pm 13.6$ & $61.0 \pm 15.3$ \\
\hline Gender ( $\mathrm{M}: \mathrm{F})$ & $20: 12$ & $13: 14$ \\
\hline Duration of pain (months) & $33.0 \pm 45.0$ & $26.5 \pm 23.8$ \\
\hline \multicolumn{3}{|l|}{ Diagnosis } \\
\hline Stenosis & $15(46.9 \%)$ & $14(51.9 \%)$ \\
\hline HNP & $12(37.5 \%)$ & $7(25.9 \%)$ \\
\hline Other & $5(15.6 \%)$ & $6(22.2 \%)$ \\
\hline
\end{tabular}

By Mann Whitney $U$ test. Values expressed as mean \pm SD or as the number (percentage).

Table 2. Numeric Rating Scales of Subjects

\begin{tabular}{cccccc}
\hline Group & Pre-treat & $\begin{array}{c}\text { Post } \\
2 \text { weeks }\end{array}$ & $\begin{array}{c}\text { Post } \\
\text { months }\end{array}$ & P value \\
\hline Morphine $(n=29)$ & $7.0(1.1)$ & $3.4(1.9)^{\star}$ & $3.6(1.9)^{\star}$ & 0.000 \\
Tramadol $(n=27)$ & $6.6(1.2)$ & $3.7(1.3)^{\star}$ & $4.1(1.6)^{\star}$ & 0.000 \\
\hline
\end{tabular}

${ }^{*} P=0.000$ compared with pre-treat. By Friedman test and Wilcoxon's signed test. Values expressed as Mean (SD).
Mean pre-treat pain scores did not differ significantly by group (Table 2).

At 2 weeks and at 3 months after treatment, both groups had significantly lower mean pain scores $(P=$ 0.000)(Table 2), but NRS did not differ significantly between groups (Table 3 ). The proportion of patients who achieved pain relief $(<50 \%)$ was not significantly different between the groups (Table 4).

None of the patients experienced any complications, and all patients completed the follow-up visits. Of the patients given morphine, three underwent surgery.

\section{DISCUSSION}

A systematic review of 7 controlled trials found level II-1 evidence that transforaminal steroids injections is effective for the short-term relief of radicular pain [18]. Although opioid use for treatment of chronic spinal pain is uncommon, our results are consistent with this previous evidence.

In studying the effects of transforaminal tramadol, Wewalka et al. [14] recorded pain relief for most (>90\%) of their 65 infiltration (37 subjects) within 24 hours, with average pain reduction of $64 \%$. Six months post-injection, 23 of the 34 patients available for follow-up (67.6\%) had successful pain reduction of $84 \%$ on average. Similarly,

Table 3. Comparison of Numeric Rating Scale Between Morphine and Tramadol

\begin{tabular}{llll}
\multicolumn{1}{c}{ Follow-up } & $\begin{array}{c}\text { Morphine } \\
(n=29)\end{array}$ & $\begin{array}{c}\text { Tramdol } \\
(n=27)\end{array}$ & P value \\
Pre-treat & $7.0(1.1)$ & $6.6(1.2)$ & 0.209 \\
Post 2 weeks & $3.4(1.9)$ & $3.7(1.3)$ & 0.528 \\
Post 3 months & $3.6(1.9)$ & $4.1(1.6)$ & 0.084
\end{tabular}

By Mann Whitney U test. Values expressed as Mean (SD).

Table 4. Pain Reduction by Numeric Rating Scale ( $\triangle$ NRS \%)

\begin{tabular}{lccccc}
\multicolumn{2}{c}{ Morphine } & \multicolumn{2}{c}{ Tramadol } \\
\cline { 2 - 5 } & 2 weeks $(n=32)$ & 3 months $(n=29)$ & 2 weeks $(n=27)$ & 3 months $(n=27)$ \\
Mean reduction ratio & $44.3 \pm 31.4$ & $47.8 \pm 25.4$ & $42.8 \pm 17.0$ & $37.3 \pm 20.4$ \\
No. with NRS reduction $50 \%>$ & $(-33.3-87.5)$ & $(0-78.0)$ & $(0-75)$ & $(-16.7-75)$ & 10
\end{tabular}

By Mann Whitney $U$ test. Values expressed mean \pm SD (ranges), ( $\triangle$ NRS \%) means post NRS minus pre-treat NRS. 
Glynn et al. [19] used epidural morphine to treat patients with arachinoiditis, low back pain, and post-operative scar pain.

In the present study, the outcomes of TFEI for lumbar radicular pain did not differ significantly whether morphine or tramadol was used, but patients given morphine did trend toward greater pain reduction. Morphine is a relatively hydrophilic opioid, thought to disperse well in cerebrospinal fluid. The severity of chronic low back pain may depend more on body weight and psychological factors, rather than true the pathology such as the low-grade systemic inflammation that causes acute sciatic pain [20]. Although the anti-inflammatory actions of opioids are not well known or well understood, the analgesia generated by opioids result from the inhibition of both sensory neuron excitability and of pro-inflammatory neuropeptide release $[12,13]$. Also of note, the duration of analgesia is significant longer with lumbar morphine than with tramadol [10,21]. In present study, 3 patients had subsequent surgery during follow-up due to lack of pain reduction. These 3 patients had more increased pain pre-procedurally and well pain relief post-operatively.

In the present study, there were no morphine-, or tramadol-related complications or side effects. The limited dosages used may offer some explanation. In a study in dogs, the epidural combination of low dose bupivacaine $(0.25 \mathrm{mg} / \mathrm{kg})$ and morphine $(0.1 \mathrm{mg} / \mathrm{kg})$ was shown to have little effect on postoperative motor function [22]. However, incidences of allergic rash, itching, sedation and respiratory depression and sedation score were higher in the morphine group than in the tramadol group [9].

We found no reference doses for morphine as a transforaminal injection in human that we used $2.5 \mathrm{mg}$ in the present study [16]. However, Krane and colleagues [23] have shown that the mean duration of analgesia is significantly longer after $0.1 \mathrm{mg} / \mathrm{kg}$. Further study is needed to determine the optimum morphine dosage under these circumstances.

One limitation of our study is that the significant improvements in pain that we identified were not corroborated with any secondary outcomes. Second, we did not assess early post-treatment pain score $(<24$ hrs or at 1 week) and no mid- or long-term follow up was pursued. Also of concern is fact that injectate volumes were not uniform, which may have bearing on pain relief. Although outcome of small $(2 \mathrm{ml})$ and larger volumes $(8 \mathrm{ml})$ of steroid injectate were comparable by lumbar TFEI [24], 95\% of the injectate dispersed superior to the level intended when more than $2.8 \mathrm{ml}$ of contrast was injected [25]. Finally, our patients were not differentiated by nature of pain (ie, neurogenic claudication or resting, spontaneous pain).

In conclusion, although local anesthetic and corticosteroid combination is typically used for TFEI of lumbar spine, the choice of drugs used for this kind of intervention remains controversial. This study showed that the quality of TFEI analgesia achieved with either morphine $(2.5 \mathrm{mg})$ or tramadol $(25 \mathrm{mg}$ ) was similar, with morphine trending to ward greater (albeit not statistically significant) relief of radicular pain.

\section{REFERENCES}

1. Olmarker K, Byröd G, Cornefjord M, Nordborg C, Rydevik B. Effects of methylprednisolone on nucleus pulposus-induced nerve root injury. Spine (Phila Pa 1976) 1994; 19: 1803-8.

2. Saal JS, Franson RC, Dobrow R, Saal JA, White AH, Goldthwaite N. High levels of inflammatory phospholipase A2 activity in lumbar disc herniations. Spine (Phila Pa 1976) 1990; 15: 674-8.

3. Slipman CW, Chow DW. Therapeutic spinal corticosteroid injections for the management of radiculopathies. Phys Med Rehabil Clin N Am 2002; 13: 697-711.

4. Manchikanti L, Buenaventura RM, Manchikanti KN, Ruan X, Gupta S, Smith HS, et al. Effectiveness of therapeutic lumbar transforaminal epidural steroid injections in managing lumbar spinal pain. Pain Physician 2012; 15: E199-245.

5. Roy C, Chatterjee N. CT-guided transforaminal epidural injections with local anesthetic, steroid, and tramadol. Pain Physician 2012; 15: E348.

6. Roberts ST, Willick SE, Rho ME, Rittenberg JD. Efficacy of lumbosacral transforaminal epidural steroid injections: a systematic review. PM R 2009; 1: 657-68.

7. Ng L, Chaudhary N, Sell P. The efficacy of corticosteroids in periradicular infiltration for chronic radicular pain: a randomized, double-blind, controlled trial. Spine (Phila Pa 1976) 2005; 30: 857-62.

8. Park $\mathrm{CH}$, Lee $\mathrm{SH}$. Investigation of high-sensitivity C-reactive protein and erythrocyte sedimentation rate in low back pain patients. Korean J Pain 2010; 23: 147-50.

9. Demiraran Y, Kocaman B, Akman RY. A comparison of the postoperative analgesic efficacy of single-dose epidural tramadol versus morphine in children. $\mathrm{Br} J$ Anaesth 2005; 95: 510-3.

10. Turker G, Goren S, Bayram S, Sahin S, Korfali G. Comparison of lumbar epidural tramadol and lumbar epidural morphine for pain relief after thoracotomy: a repeated-dose study. J 
Cardiothorac Vasc Anesth 2005; 19: 468-74.

11. George MJ. The site of action of epidurally administered opioids and its relevance to postoperative pain management. Anaesthesia 2006; 61: 659-64.

12. Stein C, Lang LJ. Peripheral mechanisms of opioid analgesia. Curr Opin Pharmacol 2009; 9: 3-8.

13. Sehgal N, Smith HS, Manchikanti L. Peripherally acting opioids and clinical implications for pain control. Pain Physician 2011; 14: 249-58.

14. Wewalka M, Abdelrahimsai A, Wiesinger GF, Uher EM. CTguided transforaminal epidural injections with local anesthetic, steroid, and tramadol for the treatment of persistent lumbar radicular pain. Pain Physician 2012; 15: 153-9.

15. Senel AC, Akyol A, Dohman D, Solak M. Caudal bupivacaine-tramadol combination for postoperative analgesia in pediatric herniorrhaphy. Acta Anaesthesiol Scand 2001; 45: 786-9.

16. Castagnera L, Maurette P, Pointillart V, Vital JM, Erny P, Sénégas J. Long-term results of cervical epidural steroid injection with and without morphine in chronic cervical radicular pain. Pain 1994; 58: 239-43.

17. Lee CR, McTavish D, Sorkin EM. Tramadol. A preliminary review of its pharmacodynamic and pharmacokinetic properties, and therapeutic potential in acute and chronic pain states. Drugs 1993; 46: 313-40.

18. Buenaventura RM, Datta S, Abdi S, Smith HS. Systematic review of therapeutic lumbar transforaminal epidural steroid injections. Pain Physician 2009; 12: 233-51.
19. Glynn C, Dawson D, Sanders R. A double-blind comparison between epidural morphine and epidural clonidine in patients with chronic non-cancer pain. Pain 1988; 34: 123-8.

20. Stürmer T, Raum E, Buchner M, Gebhardt K, Schiltenwolf M, Richter $W$, et al. Pain and high sensitivity $C$ reactive protein in patients with chronic low back pain and acute sciatic pain. Ann Rheum Dis 2005; 64: 921-5.

21. Natalini CC, Robinson EP. Evaluation of the analgesic effects of epidurally administered morphine, alfentanil, butorphanol, tramadol, and U50488H in horses. Am J Vet Res 2000; 61: 1579-86.

22. Abelson AL, Armitage-Chan E, Lindsey JC, Wetmore LA. A comparison of epidural morphine with low dose bupivacaine versus epidural morphine alone on motor and respiratory function in dogs following splenectomy. Vet Anaesth Analg 2011; 38: 213-23.

23. Krane EJ, Tyler DC, Jacobson LE. The dose response of caudal morphine in children. Anesthesiology 1989; 71: 48-52.

24. Lee $\mathrm{JH}$, An JH, Lee SH. Comparison of the effectiveness of interlaminar and bilateral transforaminal epidural steroid injections in treatment of patients with lumbosacral disc herniation and spinal stenosis. Clin J Pain 2009; 25: 206-10.

25. Furman MB, Mehta AR, Kim RE, Simon JI, Patel R, Lee TS, et al. Injectate volumes needed to reach specific landmarks in lumbar transforaminal epidural injections. PM R 2010; 2: 625-35. 